\title{
Bioactivity of compounds from Acmella oleracea against Tuta absoluta (Meyrick) (Lepidoptera: Gelechiidae) and selectivity to two non-target species
}

\author{
Shaiene C Moreno, ${ }^{\text {a* }}$ Geraldo A Carvalho, ${ }^{\text {a Marcelo C Picanço, }}$ \\ Elisangela GF Morais ${ }^{c}$ and Rogério M Pereira ${ }^{b}$
}

\begin{abstract}
BACKGROUND: Tropical plants are recognised sources of bioactive compounds that can be used for pest control. The objective of this study was to evaluate the biological activity of compounds present in Acmella oleracea (Asteracea) against Tuta absoluta (Meyrick) (Lepidoptera: Gelechiidae), which is the main pest of tomato crops in Latin America. The selectivity of these compounds to the predator Solenopsis saevissima (Smith) (Hymenoptera: Formicidae) and to the pollinator Tetragonisca angustula (Latr.) (Hymenoptera: Apidae: Meliponinae) was also of interest.
\end{abstract}

RESULTS: A bioassay screening with hexane and ethanol extracts from 23 plants was performed. The hexane extract of $A$. oleraceae was the most active of the extracts and was selected for further study. The following three alkamides were isolated from a hexane extract of the aerial parts of $A$. oleracea: spilanthol, $(E)-N$-isobutylundeca-2-en-8, 10-diynamide and $(R, E)-N-(2-$ methylbutyl)undeca-2-en-8,10-diynamide. All of the isolated compounds showed insecticidal activity, with spilanthol being the most active $\left(\operatorname{LD}_{50}=0.13 \mu \mathrm{g} \mathrm{mg}^{-1}\right.$ ) against $T$. absoluta. The alkamides were selective to both beneficial species studied.

CONCLUSION: The crude hexane extract of $A$. oleraceae showed high insecticidal activity and can be used to control $T$. absoluta in organic or conventional crops. Quantification of LD $_{50}$ values of isolated compounds against $T$. absoluta showed that alkamides could serve as potent insecticides for $T$. absoluta control programmes. Spilanthol was the main alkamide active isolated. This alkamide is the most promising as it has the highest insecticidal activity and is selective to non-target organisms.

(c) 2011 Society of Chemical Industry

Keywords: botanical pesticide; insect control; secondary metabolites; bioactive alkamides; tomato leafminer

\section{INTRODUCTION}

The tomato leafminer, Tuta absoluta (Meyrick) (Lepidoptera: Gelechiidae), is a neotropical oligophagous insect that attacks solanaceous crops. ${ }^{1}$ Since the 1960s, it has become one of the key pests of tomato crops in most South American countries. ${ }^{2}$ Recently, T. absoluta has also become a serious threat to tomato production in the Mediterranean region. ${ }^{3}$ Following detection in the Spanish tomato-growing area at the end of 2006, T. absoluta spread quickly to other European and northern African countries. ${ }^{4,5}$ The larvae attack tomato plants during all growth stages, producing large galleries in their leaves, burrowing stalks, apical buds and green and ripe fruits.

Chemical control has been the main method of control used against T. absoluta. Horticultural growers have attempted to decrease the damage caused by $T$. absoluta by applying insecticides more than 2 times a week during a single cultivation period. ${ }^{2}$ Tuta absoluta control is a challenge owing to the nature of the damage it causes and its rapid ability to develop resistance towards conventional insecticides. ${ }^{1,6}$ Thus, there is an urgent need to develop safe alternatives to conventional insecticides for the protection of tomato plants against T. absoluta.

The use of ecofriendly and easily biodegradable plant products with natural insecticidal activity has increased in recent years. To control pests without disturbing the environment, natural products have been screened for potential sources of insecticides. Plant materials with insecticidal properties have been used to kill insects throughout the world for generations. These plants are considered to be an alternative to conventional pesticides

\footnotetext{
Correspondence to: Shaiene CMoreno, Departamento de Entomologia, Universidade Federal de Lavras, 27200-000, Lavras, MG, Brazil. E-mail: shaiene.moreno@ifrj.edu.br

a Departamento de Entomologia, Universidade Federal de Lavras, Lavras, MG, Brazil

b Departamento de Biologia Animal, Universidade Federal de Viçosa, Viçosa, MG, Brazil

c Embrapa Roraima, Distrito Industrial, Boa Vista, RR, Brazil
} 
because of their low toxicity to warm-blooded mammals as well as their high volatility. Botanical insecticides may be safer for the environment than synthetic insecticides, and they are usually easily processed and used by farmers and small industries. ${ }^{7}$

Tropical plants are recognised sources of bioactive compounds, but less than $1 \%$ have been chemically investigated. ${ }^{8}$ They can be used for pest control as plant extracts, horticultural oils or as a source of molecules for pesticide synthesis such as pyrethroids and neonicotinoids.

Acmella oleracea (L.) RK Jansen [synonyms: Spilanthes oleracea L. and Spilanthes acmella auct. non (L.) Murr.] is an annual plant of the family Asteraceae (Compositae) originating in the tropics of Brazil. The distribution covers tropical and subtropical areas around the world, and it is known in English as toothache plant or paracress, and in Portuguese as jambú. ${ }^{9}$ The inflorescence is composed of yellow flowers, and the leaves have a pungent flavour accompanied with tingling and numbness. The plant has been used in cooking and in popular medicine, mainly for stammering, toothache, stomatitis and throat complaints.

The plant contains alkamides including spilanthol, which is the principal pungent compound. This chemical compound is known for having several chemical and pharmaceutical applications. It has shown anti-inflammatory, antibacterial, antifungal, diuretic, sialagogic and larvicidal properties. ${ }^{9}$ The activity of $A$. oleracea has been studied extensively. However, only a few studies have assessed the insecticidal activity of compounds from this plant. Furthermore, the majority of these studies have focused on human health pests. ${ }^{10-13}$ These studies show that compounds of $A$. oleracea have high insecticidal activity against insect vectors of diseases. Therefore, the potential use of this plant species for management of agricultural pests requires further investigation.

New compounds should provide selectivity to non-target species, especially predators and pollinators, in addition to efficiency against insect pests. Attack by natural enemies is the most frequent source of mortality for phytophagous arthropods in agroecosystems, and the conservation of these organisms is an essential component in integrated pest management (IPM). ${ }^{14}$ Furthermore, pollination is central for successful reproduction in most plants. Thus, pollinators should be preserved because they support the maintenance of biodiversity in the ecosystems they inhabit. ${ }^{15}$ Although most tomato plants need no assistance with pollinating, the presence of insects that visit flowers is important to promote the vibrancy of the flowers and allow self-pollination. In agroecosystems there are many species that are part of these groups, including the predator Solenopsis saevissima (Smith) (Hymenoptera: Formicidae) and the pollinator Tetragonisca angustula (Latr.) (Hymenoptera: Apidae: Meliponinae). The predation by S. saevissima has played an important role in reducing pest insects in agricultural systems. Way and Khoo ${ }^{16}$ cited species of the genus Solenopsis as important agents of biological control in the tropics and subtropics. Tetragonisca angustula is one of the most common stingless bees in the Neotropical region. Stingless bees are generalist foragers and are efficient native pollinators of the American flora. ${ }^{15}$

Considering the potential of tropical plant species for pest control and the importance of T. absoluta, the aims of this study were to screen plants with insecticide activity to $T$. absoluta. The goal was to isolate, identify and assess the bioactivity of insecticide compounds present in the bioactive plant against this key insect pest of tomato crops. Furthermore, the selectivity of these compounds to the beneficial insects $S$. saevissima and T. angustula was of interest.

\section{MATERIALS AND METHODS}

\subsection{Insects}

The bioassays were performed with second-instar larvae of T. absoluta and adults of S. saevissima and T. angustula. Larvae of $T$. absoluta were obtained from a laboratory rearing located at the campus of the Universidade Federal de Viçosa (UFV), Viçosa, Minas Gerais State, Brazil. Adults of S. saevissima and T. angustula were collected from nests located around the campus of the UFV.

\subsection{Plant screening}

\subsubsection{Plant extract preparation}

Table 1 describes the plants that were used for extraction and toxicity bioassays. The plants were chosen on the basis of available literature, popular or indigenous knowledge and chemotaxonomy. The plant material was identified in the botanical park of the Federal University of Acre.

Samples of $1.0 \mathrm{~kg}$ from the canopy of each plant species were collected in Rio Branco, AC, Brazil (plants of the Amazon Biome), and in Viçosa, MG, Brazil (plants of the Cerrado and of general occurrence). Each sample was lyophilised, and the dried material was crushed and placed in a 2 L Erlenmeyer flask, with enough hexane to submerge the plant material. After $48 \mathrm{~h}$, the solvent was removed under filtration. Ethanol extraction was performed by grinding the samples with the solvent (100\% ethanol) and waiting for $48 \mathrm{~h}$. The hexane and ethanol extracts were concentrated under low pressure and reduced temperature $\left(<50^{\circ} \mathrm{C}\right)$. The yield for each extract is shown in Table 1. The plant extracts were stored at low temperature for subsequent bioassays.

\subsubsection{Screening bioassay}

A set of screening bioassays was performed to identify the bioactive plant extracts to T. absoluta. The stored extracts were diluted with acetone to a dose of $10 \mu \mathrm{g} \mathrm{mg}^{-1}$ body mass. The average weight was obtained by measuring the mass of ten groups containing ten insects each on an analytical balance. The experimental design was completely randomised with six replications. Each experimental unit consisted of a glass petri dish $(9.5 \mathrm{~cm} \times 2.0 \mathrm{~cm})$ containing ten insects.

The bioassays were conducted by topical application. For each insect, a $10 \mu \mathrm{L}$ Hamilton microsyringe was used to add $0.5 \mu \mathrm{L}$ of a solution of the test extract. In a control experiment under the same conditions, $0.5 \mu \mathrm{L}$ of hexane was applied on each insect.

After the application, the insects were kept in individual petri dishes containing tomato leaflets (cv. Santa Clara) as food. The petri dishes were placed in an incubator at $25 \pm 0.5^{\circ} \mathrm{C}$ and $75 \pm 5 \%$ relative humidity with a photoperiod of $12 \mathrm{~h}$. The mortality counts were made after 6,12 and $24 \mathrm{~h}$ of treatment. Mortality included dead individuals as well as those without movements. Mortality data were subjected to analysis of variance, and the averages were compared by the Scott-Knott grouping analysis test $(P<0.05)$.

\subsection{Bioactivity of compounds from A. oleracea}

\subsubsection{Extract preparation of A. oleracea}

The hexane extract of $A$. oleracea, which showed the highest insecticidal activity in the screening bioassay, was selected for isolation and structure elucidation of its bioactive compounds. A total of $2.0 \mathrm{~kg}$ of dried and powdered aerial parts of Acmella oleracea was used for this purpose. The solvent (hexane) was changed every 2 days for 45 days. The extraction continued until the solvent was colourless. The filtered extract obtained was concentrated in a rotary vacuum evaporator under low pressure and reduced temperature $\left(<50^{\circ} \mathrm{C}\right)$. 
Table 1. Identification of plants used in screening bioassays (scientific name and family) and yield of hexane and ethanol extracts obtained from $1.0 \mathrm{~kg}$ of the plant aerial parts

\begin{tabular}{|c|c|c|c|c|}
\hline \multirow[b]{2}{*}{ No. } & \multirow[b]{2}{*}{ Scientific name } & \multirow[b]{2}{*}{ Family } & \multicolumn{2}{|c|}{ Yield (g) } \\
\hline & & & Hexane extract & Ethanol extract \\
\hline \multicolumn{5}{|c|}{ Plants of the Amazon Biome } \\
\hline 1 & Acmella oleracea $\mathrm{L}$. & Asteraceae & 10.74 & 15.04 \\
\hline 2 & Banara guianensis Aubl. & Flacourtiaceae & 22.74 & 26.54 \\
\hline 3 & Banara nitida Spruce ex Benth. & Flacourtiaceae & 4.2 & 10.49 \\
\hline 4 & Clavija weberbaueri Mez. & Theophrastaceae & 5.42 & 35.88 \\
\hline 5 & Copaifera duckei Dwyer & Caesalpinioideae & 7.42 & 18.44 \\
\hline 6 & Eugenia egensis DC. & Myrtaceae & 7.42 & 18.44 \\
\hline 7 & Mayna parvifolia Sleumer & Flacourtiaceae & 16.95 & 9.23 \\
\hline 8 & Piper aduncum L. & Piperaceae & 7.6 & 11.58 \\
\hline 9 & Piper augustum Rudge & Piperaceae & 7.86 & 21.33 \\
\hline 10 & Ryania speciosa Vahl. & Flacourtiaceae & 8.96 & 77.34 \\
\hline 11 & Siparuna amazônica Mart. ex A. DC. & Monimiaceae & 10.43 & 36.3 \\
\hline \multicolumn{5}{|c|}{ Plant of the Cerrado Biome } \\
\hline 12 & Curatela americana $\mathrm{L}$. & Dilleniaceae & 13.26 & 19.87 \\
\hline \multicolumn{5}{|c|}{ Plants of general occurrence } \\
\hline 13 & Ageratum conyzoides L. & Asteraceae & 12.00 & 25.24 \\
\hline 14 & Allamanda cathartica $\mathrm{L}$. & Apocynaceae & 5.31 & 4.51 \\
\hline 15 & Argemone mexicana L. & Papaveraceae & 5.98 & 6.48 \\
\hline 16 & Artemisia vulgaris $\mathrm{L}$. & Asteraceae & 4.47 & 6.81 \\
\hline 17 & Bauhinia variegate $\mathrm{L}$. & Caesalpinioideae & 11.48 & 32.02 \\
\hline 18 & Bougainvillea glabra Choisy & Nyctaginaceae & 7.56 & 9.63 \\
\hline 19 & Calendula officinalis $\mathrm{L}$. & Asteraceae & 4.30 & 5.81 \\
\hline 20 & Chenopodium ambrosioides $\mathrm{L}$. & Chenopodiaceae & 4.75 & 6.38 \\
\hline 21 & Coriandrum sativum L. & Apiaceae & 5.59 & 7.52 \\
\hline 22 & Spathodea campanulata P. Beauv. & Bignoniaceae & 12.70 & 28.76 \\
\hline 23 & Tropaeolum majus L. & Tropaeolaceae & 6.32 & 7.21 \\
\hline
\end{tabular}

\subsubsection{Isolation and structural elucidation of bioactive compounds}

Fractionation of the hexane extract $(28 \mathrm{~g})$ was performed by column chromatography (silica gel 60, 63-200 $\mu \mathrm{m}$ particle size, 70-230 mesh) using hexane with increasing amounts of ethyl acetate and finally with methanol as the eluting solvents. Thin-layer chromatography (TLC) (silica gel 60 F254, $0.25 \mathrm{~mm}$ ) was used to identify fractions containing similar compounds. The TLC spots were detected under UV ( 254 and $365 \mathrm{~nm}$ ) as well as by heating the plates to $100^{\circ} \mathrm{C}$ after spraying with phosphomolybdic acid/ethylic alcohol. Eight fractions ( $\mathrm{A}$ to $\mathrm{H}$ ) were collected and subjected to bioassay with $T$. absoluta using the same methods as described in Section 2.2.2. The most toxic fractions were purified by preparative TLC of Merck silica gel 60 F254 $(20 \times 20 \mathrm{~cm}$ plates, $0.75 \mathrm{~mm}$ adsorbent). The different zones separated through preparative TLC were scraped from the silica plate and were collected in separate test tubes. Ethyl acetate $(100 \mathrm{~mL})$ was added to each test tube. Thereafter, the ethyl acetate containing dissolved compounds was filtered twice through filter paper (125 mm diameter) to remove any suspended silica powder completely. The bioactive fraction $F$ was purified using hexane-ethyl acetate $(6: 1)$ as the mobile phase to yield the following three major bands: I (725 mg), II (56 mg) and III (21 mg). Band I was further purified using hexane-ethyl acetate ( $1: 2$ ) to give compounds 1 and $\mathbf{2}$ (320 and $210 \mathrm{mg}$ respectively). The bioactive fraction $\mathrm{G}$ was purified with hexane-ethyl acetate $(3: 1)$ as eluent to yield compound 3 ( $27 \mathrm{mg}$ ). The IR spectra of isolated compounds were recorded on $\mathrm{KBr}$ in a Paragon 1000 FTIR infrared spectrometer (Perkin Elmer, Wellesley, MA) from 600 to $4000 \mathrm{~cm}^{-1}$. GC-MS was conducted with a Shimadzu QP5050A gas chromatograph-mass spectrometer. To identify the isolated compounds, ${ }^{1} \mathrm{H}$ NMR and ${ }^{13} \mathrm{C}$ NMR were recorded in a Bruker WM 400 spectrometer (Bruker Optics Inc., Billerica, $\mathrm{MA}$ ) using $\mathrm{CDCl}_{3}$ as a solvent and TMS as an internal standard.

\subsubsection{Dose-mortality bioassays}

The isolated compounds and the hexane extract of $A$. oleraceae were subject to toxicity bioassays against T. absoluta, S. saevissima and $T$. angustula. The insecticidal activity of neem (Azadirachta indica A. Juss) seed kernel hexane extract and of permethrin (92.2\% purity; Syngenta), a synthetic derivative of the natural pyrethrins recommended for T. absoluta control, were also evaluated and used as positive controls. The experimental design was completely randomised with six replications. Each experimental unit consisted of a glass petri dish $(9.5 \mathrm{~cm} \times 2.0 \mathrm{~cm})$ containing ten insects. The average weight of each insect species was obtained by measuring the mass of ten groups containing ten insects each on an analytical balance.

Initially, four doses of each compound were tested to identify the range of concentrations that would provide mortalities greater than zero and less than $100 \%$. Once the range of concentrations was defined, other doses were tested for each compound. The number of doses used to obtain the dose-mortality curves varied from five to eight doses.

Bioassays were conducted by topical application. For each insect, a $10 \mu \mathrm{L}$ Hamilton microsyringe was used to apply $0.5 \mu \mathrm{L}$ 
Table 2. Contact toxicity of plant extracts at a concentration of $10 \mu \mathrm{g}$ of extract per mg of insect against Tuta absoluta 6,12 and $24 \mathrm{~h}$ after topical application

\begin{tabular}{|c|c|c|c|c|c|c|}
\hline \multirow[b]{3}{*}{ Plants } & \multicolumn{6}{|c|}{ Mean percentage mortality ${ }^{a}$} \\
\hline & \multicolumn{2}{|c|}{$6 \mathrm{~h}$ after topical exposure } & \multicolumn{2}{|c|}{$12 \mathrm{~h}$ after topical exposure } & \multicolumn{2}{|c|}{$24 \mathrm{~h}$ after topical exposure } \\
\hline & Ethanol extract & Hexane extract & Ethanol extract & Hexane extract & Ethanol extract & Hexane extract \\
\hline Acmella oleracea & $88.3( \pm 1.5) \mathrm{Ab}$ & $100.0( \pm 0.0) \mathrm{Aa}$ & $88.3( \pm 1.5) \mathrm{Ab}$ & $100.0( \pm 0.0) \mathrm{Aa}$ & $88.3( \pm 1.5) \mathrm{Ab}$ & $100.0( \pm 0.0) \mathrm{Aa}$ \\
\hline Ageratum conyzoides & $26.7( \pm 1.9) \mathrm{Bb}$ & $45.0( \pm 2.0) \mathrm{Ba}$ & $35.0( \pm 3.1) \mathrm{Bb}$ & $48.3( \pm 2.8) \mathrm{Ca}$ & $35.0( \pm 3.1) \mathrm{Bb}$ & $51.7( \pm 3.1) \mathrm{Ca}$ \\
\hline Allamanda cathartica & $21.7( \pm 2.8) \mathrm{Ba}$ & $18.3( \pm 2.1) \mathrm{Da}$ & $21.7( \pm 2.8) \mathrm{Ba}$ & $23.3( \pm 1.9) \mathrm{Ea}$ & $25.0( \pm 3.4) \mathrm{Ba}$ & $23.3( \pm 3.3) \mathrm{Ca}$ \\
\hline Argemone mexicana & $25.0( \pm 3.1) \mathrm{Ba}$ & $20.0( \pm 2.4) \mathrm{Da}$ & $25.0( \pm 3.1) \mathrm{Bb}$ & $33.3( \pm 2.8) \mathrm{Ea}$ & $28.3( \pm 3.1) \mathrm{Bb}$ & $41.7( \pm 3.1) \mathrm{Ca}$ \\
\hline Artemisia vulgaris & $5.0( \pm 2.0) \mathrm{Da}$ & $6.7( \pm 1.9) \mathrm{Ea}$ & $13.3( \pm 1.9) \mathrm{Ba}$ & $8.3( \pm 1.7) \mathrm{Gb}$ & $15.0( \pm 2.2) \mathrm{Ca}$ & $8.3( \pm 1.7) \mathrm{Eb}$ \\
\hline Banara guianensis & $26.7( \pm 1.9) \mathrm{Ba}$ & $28.3( \pm 2.8) \mathrm{Ca}$ & $36.7( \pm 3.3) \mathrm{Ba}$ & $33.3( \pm 3.6) \mathrm{Ea}$ & $36.7( \pm 3.3) \mathrm{Ba}$ & $41.7( \pm 4.0) \mathrm{Ca}$ \\
\hline Banara nitida & $16.7( \pm 3.7) \mathrm{Ca}$ & $13.3( \pm 2.9) \mathrm{Ea}$ & $23.3( \pm 3.3) \mathrm{Ba}$ & $18.3( \pm 1.7) \mathrm{Fa}$ & $23.3( \pm 3.3) \mathrm{Ba}$ & $18.3( \pm 1.7) \mathrm{Da}$ \\
\hline Bauhinia variegate & $6.7( \pm 3.1) \mathrm{Da}$ & $8.3( \pm 2.8) \mathrm{Ea}$ & $11.7( \pm 1.7) \mathrm{Ba}$ & $15.0( \pm 2.2) \mathrm{Fa}$ & $11.7( \pm 1.7) \mathrm{Ca}$ & $15.0( \pm 2.2) \mathrm{Da}$ \\
\hline Bougainvillea glabra & $25.0( \pm 3.1) \mathrm{Bb}$ & $42.5( \pm 2.5) \mathrm{Ba}$ & $33.3( \pm 2.1) \mathrm{Bb}$ & $42.5( \pm 2.5) \mathrm{Da}$ & $33.3( \pm 2.1) \mathrm{Bb}$ & $51.7( \pm 3.1) \mathrm{Ca}$ \\
\hline Calendula officinalis & $13.3( \pm 1.9) \mathrm{Ca}$ & $6.7( \pm 1.9) \mathrm{Eb}$ & $13.3( \pm 1.9) \mathrm{Ba}$ & $15.0( \pm 2.2) \mathrm{Fa}$ & $13.3( \pm 3.3) \mathrm{Ca}$ & $15.0( \pm 2.2) \mathrm{Da}$ \\
\hline Chenopodium ambrosioides & $15.0( \pm 2.0) \mathrm{Ca}$ & $16.7( \pm 3.3) \mathrm{Da}$ & $16.7( \pm 3.3) \mathrm{Ba}$ & $16.7( \pm 3.3) \mathrm{Fa}$ & $16.7( \pm 3.3) \mathrm{Ca}$ & $21.7( \pm 3.1) \mathrm{Ca}$ \\
\hline Clavija weberbaueri & $25.0( \pm 2.2) \mathrm{Ba}$ & $28.3( \pm 2.8) \mathrm{Ca}$ & $25.0( \pm 2.2) \mathrm{Bb}$ & $36.7( \pm 3.3) \mathrm{Ea}$ & $25.0( \pm 2.2) \mathrm{Bb}$ & $36.7( \pm 3.3) \mathrm{Ca}$ \\
\hline Copaifera duckei & $36.7( \pm 3.3) \mathrm{Bb}$ & $50.0( \pm 4.1) \mathrm{Ba}$ & $36.7( \pm 3.3) \mathrm{Bb}$ & $63.3( \pm 3.3) \mathrm{Ba}$ & $36.7( \pm 3.3) \mathrm{Bb}$ & $63.3( \pm 3.3) \mathrm{Ba}$ \\
\hline Coriandrum sativum & $18.3( \pm 1.7) \mathrm{Cb}$ & $41.7( \pm 2.8) \mathrm{Ba}$ & $21.7( \pm 1.7) \mathrm{Bb}$ & $48.3( \pm 2.8) \mathrm{Ca}$ & $21.7( \pm 1.7) \mathrm{Bb}$ & $66.7( \pm 3.3) \mathrm{Ba}$ \\
\hline Curatela americana & $31.7( \pm 2.8) \mathrm{Ba}$ & $30.0( \pm 3.3) \mathrm{Ca}$ & $41.7( \pm 3.1) \mathrm{Ba}$ & $30.0( \pm 3.3) \mathrm{Eb}$ & $41.7( \pm 3.1) \mathrm{Bb}$ & $48.3( \pm 1.7) \mathrm{Ca}$ \\
\hline Eugenia egensis & $30.0( \pm 2.6) \mathrm{Ba}$ & $16.7( \pm 1.9) \mathrm{Db}$ & $30.0( \pm 2.6) \mathrm{Ba}$ & $28.3( \pm 2.8) \mathrm{Ea}$ & $30.0( \pm 2.6) \mathrm{Ba}$ & $36.7( \pm 2.1) \mathrm{Ca}$ \\
\hline Mayna parvifolia & $26.7( \pm 3.3) \mathrm{Ba}$ & $20.0( \pm 2.4) \mathrm{Da}$ & $26.7( \pm 3.3) \mathrm{Ba}$ & $30.0( \pm 3.6) \mathrm{Ea}$ & $26.7( \pm 3.3) \mathrm{Ba}$ & $30.0( \pm 3.6) \mathrm{Ca}$ \\
\hline Piper aduncum & $33.3( \pm 2.1) \mathrm{Ba}$ & $35.0( \pm 2.2) \mathrm{Ca}$ & $33.3( \pm 2.1) \mathrm{Ba}$ & $35.0( \pm 2.2) \mathrm{Ea}$ & $33.3( \pm 2.1) \mathrm{Ba}$ & $35.0( \pm 2.2) \mathrm{Ca}$ \\
\hline Piper augustum & $35.0( \pm 2.2) \mathrm{Ba}$ & $18.3( \pm 1.5) \mathrm{Db}$ & $35.0( \pm 2.2) \mathrm{Ba}$ & $25.0( \pm 2.2) \mathrm{Eb}$ & $35.0( \pm 2.2) \mathrm{Ba}$ & $25.0( \pm 2.2) \mathrm{Cb}$ \\
\hline Ryania speciosa & $15.6( \pm 3.9) \mathrm{Cb}$ & $33.3( \pm 3.8) \mathrm{Ca}$ & $18.3( \pm 1.7) \mathrm{Bb}$ & $33.3( \pm 3.8) \mathrm{Ea}$ & $18.3( \pm 1.5) \mathrm{Cb}$ & $33.3( \pm 3.8) \mathrm{Ca}$ \\
\hline Siparuna amazônica & $16.7( \pm 1.9) \mathrm{Ca}$ & $20.0( \pm 2.4) \mathrm{Da}$ & $25.0( \pm 3.1) \mathrm{Ba}$ & $28.3( \pm 3.1) \mathrm{Ea}$ & $26.7( \pm 3.0) \mathrm{Ba}$ & $28.3( \pm 3.1) \mathrm{Ca}$ \\
\hline Spathodea campanulata & $3.3( \pm 1.9) \mathrm{Db}$ & $13.3( \pm 1.9) \mathrm{Ea}$ & $6.7( \pm 3.3) \mathrm{Cb}$ & $26.7( \pm 1.9) \mathrm{Ea}$ & $6.7( \pm 3.3) \mathrm{Db}$ & $26.7( \pm 1.9) \mathrm{Ca}$ \\
\hline Tropaeolum majus & $31.7( \pm 3.1) \mathrm{Ba}$ & $33.3( \pm 2.1) \mathrm{Ca}$ & $31.7( \pm 3.1) \mathrm{Ba}$ & $33.3( \pm 2.1) \mathrm{Ea}$ & $31.7( \pm 3.1) \mathrm{Ba}$ & $33.3( \pm 2.1) \mathrm{Ca}$ \\
\hline Control $^{b}$ & $0.0( \pm 0.0) \mathrm{Ea}$ & $0.0( \pm 0.0) \mathrm{Fa}$ & $0.0( \pm 0.0) \mathrm{Da}$ & $0.0( \pm 0.0) \mathrm{Fa}$ & $0.0( \pm 0.0) \mathrm{Ea}$ & $0.0( \pm 0.0) \mathrm{Fa}$ \\
\hline
\end{tabular}

of a solution of the test compound dissolved in acetone. In a control experiment, carried out under the same conditions, $0.5 \mu \mathrm{L}$ of acetone was applied to each insect.

After application, the insects were kept in individual petri dishes containing the appropriate food. T. absoluta were fed tomato leaflets (cv. Santa Clara), while S. saevissima and T. angustula both received a mixture of honey $(50 \%)$ and pure water (50\%). The mixture of honey and water was supplied in plastic containers that were $1.5 \mathrm{~cm}$ in diameter and $1.0 \mathrm{~cm}$ in height.

The petri dishes were placed in an incubator at $25 \pm 0.5^{\circ} \mathrm{C}$ and $75 \pm 5 \%$ relative humidity with a photoperiod of $12 \mathrm{~h}$. The mortality counts were made after $24 \mathrm{~h}$. Mortality included both dead individuals and those that were no longer moving. Dose-mortality data were subjected to probit analysis using SAS software (PROC PROBIT; SAS) to estimate dose-mortality curves. ${ }^{17}$ Curves that had probabilities greater than 0.05 by the $\chi^{2}$-test were accepted. ${ }^{18}$

\subsubsection{Risk assessment to non-target insects}

To determine the magnitude of selectivity of the compounds to the beneficial insects, the selectivity ratio was calculated using the formula $S_{L} R_{50}=L D_{50}$ of the insecticide for the beneficial insect per $\mathrm{LD}_{50}$ of the insecticide for T. absoluta. Values of 1 and $<1$ indicate that the chemical is non-selective to the beneficial insect. Values of $>1$ indicate that the chemical is selective and/or harmless to the beneficial insect. ${ }^{19}$ Using the dose-mortality curves, mortalities caused to beneficial insects by the doses of the compounds that caused $80 \%$ mortality in T. absoluta were also estimated.

\section{RESULTS}

\subsection{Bioactivity of plant extracts (plant screening)}

The hexane extract from aerial parts of $A$. oleracea exhibited the highest activity of all extracts, causing $100.0 \%(N=60)$ mortality in T. absoluta at a concentration of $10 \mu \mathrm{g}$ of extract per $\mathrm{mg}$ of insect after $6 \mathrm{~h}$ of exposure. The mortality caused by the solvents was zero $(0.0 \%)$ in all of the bioassays (Table 2 ).

The ethanol extract of $A$. oleracea also showed high activity (88.3\% mortality) against T. absoluta, and was the second most active extract. The hexane and ethanol extracts of the remainder of the plants tested showed low insecticidal activity towards $T$. absoluta (Table 2).

On the basis of these results, the hexane extract of $A$. oleracea was selected for isolation and structure elucidation of its bioactive compounds.

\subsection{Isolation and structural elucidation of compounds from $A$. oleracea}

To obtain bioactive compounds, the hexane extract $(28 \mathrm{~g})$ was fractionated by a bioactivity-guided fractionation approach, and 

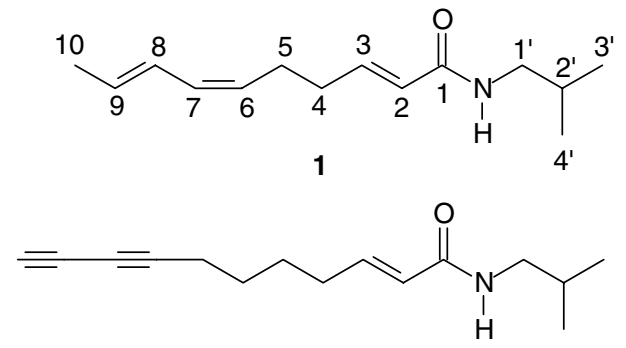

2

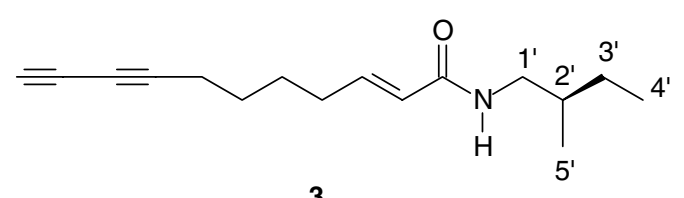

Figure 1. Structure of the three alkamides isolated from Acmella oleracea: $(2 E, 6 Z, 8 E)$ - $N$-isobutyldeca-2,6,8-trienamide (1), (E)- $N$-isobutylundeca-2en-8,10-diynamide (2) and (R,E)-N-(2-methylbutyl)undeca-2-en-8,10diynamide (3).

eight fractions ( $\mathrm{A}$ to $\mathrm{H}$ ) were obtained. The eight fractional groups were evaluated for their insecticide activity against $T$. absoluta larvae. Fractions $\mathrm{F}$ and $\mathrm{G}$ eluted with hexane-ethyl acetate $(1: 1)$ were biologically active, causing $100 \%$ mortality $6 \mathrm{~h}$ after administration of a dose of $10 \mu \mathrm{g} \mathrm{mg}^{-1}$ body mass. The remainder of the fractions ( $A, B, C, D, E$ and $H$ ) caused mortalities of less than $40 \%$.

The bioactive fraction $F$ was purified by preparative TLC (hexane-ethyl acetate, $6: 1$ ) to yield the following three major bands: I (725 mg, RF 0.65), II (56 mg, RF 0.45) and III (21 mg, RF 0.25 ). Band I was biologically active and was further purified by preparative TLC (hexane-ethyl acetate, $1: 2$ ) to give compounds 1 and $\mathbf{2}$ ( 320 and $210 \mathrm{mg}$ respectively). The bioactive fraction $\mathrm{G}$ was purified by preparative TLC (hexane-ethyl acetate, $3: 1$ ) to yield compound 3 ( $27 \mathrm{mg}$ ).

Compound 1, $(2 E, 6 Z, 8 E)$ - $N$-isobutyldeca-2,6,8-trienamide or spilanthol (Fig. 1) was isolated as a colourless oil. The IR spectrum showed the presence of a secondary amide group (3340, 1636 and $\left.1550 \mathrm{~cm}^{-1}\right)$, a double bond conjugated to an amide carbonyl group $\left(1678 \mathrm{~cm}^{-1}\right)$ and a conjugated diene group with $Z, E$ or $E, Z$ configuration $\left(987\right.$ and $\left.953 \mathrm{~cm}^{-1}\right)$. The MS spectrum had a molecular ion peak at $\mathrm{m} / \mathrm{z} 221$, which indicates the molecular formula $\mathrm{C}_{14} \mathrm{H}_{23} \mathrm{NO}$. GC-EIMS $70 \mathrm{eV}, \mathrm{m} / \mathrm{z}$ (rel. int.): $221[\mathrm{M}]^{+}(20)$, 206 (3), 141 (100), 126 (23), 98 (23), 81 (87), 69 (10), 53 (10). The ${ }^{13} \mathrm{C}$ NMR $\left(\mathrm{CDCl}_{3}\right)$ and the ${ }^{1} \mathrm{H}$ NMR $\left(\mathrm{CDCl}_{3}\right)$ spectra showed spilanthic acid. On the amine moiety, the typical signals at $\delta 3.15(2 \mathrm{H}, \mathrm{t}$, $\left.\mathrm{H}-1^{\prime}\right), 1.78\left(1 \mathrm{H}, \mathrm{m}, \mathrm{H}-2^{\prime}\right)$, and $0.93\left(6 \mathrm{H}, \mathrm{d}, \mathrm{H}-3^{\prime}, 4^{\prime}\right)$ in ${ }^{1} \mathrm{H}$ NMR and $\delta$ $46.9\left(\mathrm{C}-1^{\prime}\right), 28.6\left(\mathrm{C}-2^{\prime}\right)$ and $20.1\left(\mathrm{C}-3^{\prime}, 4^{\prime}\right)$ in ${ }^{13} \mathrm{C}$ NMR indicated the presence of an isobutylamino group. All of the spectral data were in agreement with those of spilanthol (1) in the literature..$^{20}$

Compound $\mathbf{2}$ was isolated as a colourless crystal. In the ${ }^{1} \mathrm{H}$ NMR spectrum, characteristic signals at $\delta 3.18\left(\mathrm{dd}, \mathrm{H}-\mathrm{I}^{\prime}\right), 1.79(\mathrm{~m}$, $\mathrm{H}-2^{\prime}$ ) and 0.91 ( $\mathrm{d}, \mathrm{H}-3^{\prime}$ and $\mathrm{H}-4^{\prime}$ ) indicated the isobutylamide moiety. This compound was identified as $(E)-N$-isobutylundeca2-en-8,10-diynamide (Fig. 1) by comparing its ${ }^{1} \mathrm{H}$ NMR spectral data with published values. ${ }^{21}$ The ${ }^{13} \mathrm{C}$ NMR spectrum (Table 4) was consistent with published data. ${ }^{10}$

Compound 3, $(R, E)-N$-(2-methylbutyl)undeca-2-en-8,10-diynamide (Fig. 1), was isolated as a colourless oil. The IR spectrum presented absorption bands attributable to a triple bond $\left(2225 \mathrm{~cm}^{-1}\right)$ in addition to a secondary amide group (3299, 1627 and $1554 \mathrm{~cm}^{-1}$ ) and a double bond conjugated with an amide carbonyl group $\left(1669 \mathrm{~cm}^{-1}\right)$. The ${ }^{1} \mathrm{H}$ NMR spectrum revealed signals at $\delta 5.77(\mathrm{~d}, J=15 \mathrm{~Hz})$ and $6.80(\mathrm{dt}, J=15 \mathrm{~Hz}$ and $7 \mathrm{~Hz})$ which have been attributed to olefinic protons $\mathrm{H}-2$ and $\mathrm{H}-3$ respectively. On the amine moiety, a pair of $1 \mathrm{H}$ ddq signals at $\delta 1.17$ and 1.41 are attributed to methylene protons of $\left(-3^{\prime}\right.$, and a pair of ddd signals at $\delta 3.14$ and 3.27 are attributed to methylene protons of $\mathrm{C}-1^{\prime}$ owing to the presence of asymmetric carbon at $\mathrm{C}-2^{\prime}$. The ${ }^{13} \mathrm{C}$ NMR spectrum gave rise to 16 carbon signals. Five carbon signals at $\delta 45.2,35.1,27.1,11.3$ and 17.2 confirmed a 2-methylbutylamine moiety. The ${ }^{13} \mathrm{C}$ NMR and ${ }^{1} \mathrm{H}$ NMR signals correspond well to the literature. $^{20}$

\subsection{Bioactivity of isolated compounds}

The dose-mortality results from insecticide application in larvae of T. absoluta showed low $\chi^{2}$ and high $P$-values $(<7.7$ and $>0.103$ respectively), indicating the suitability of the probit model for fitting the dose-response curves and consequently obtaining estimates of the mortality parameters $\mathrm{LD}_{50}$ and $\mathrm{LD}_{80}$ (Table 3 ).

Compound 1 (spilanthol) exhibited the highest toxicity to T. absoluta, with the lowest $\mathrm{LD}_{50}$. Furthermore, spilanthol (1) was approximately 5 times more toxic than permethrin and approximately 321 times more potent than $A$. indica extract (Table 3).

The compounds (E)- $N$-isobutylundeca-2-en-8,10-diynamide (2) and $(R, E)-N$-(2-methylbutyl)undeca-2-en-8,10-diynamide (3) showed insecticidal activity similar to that of the commercial insecticide permethrin. In comparison with the extract of $A$. indica, compounds $\mathbf{2}$ and $\mathbf{3}$ were respectively about 62 and 52 times more toxic to T. absoluta (Table 3).

The $A$. oleracea extract was less toxic than the isolated compounds, but it showed good insecticidal activity. It was 23 times more toxic than the neem extract (Table 3).

\subsection{Selectivity of isolated compounds}

The dose needed to kill $50 \%$ of the test population $\left(\mathrm{LD}_{50}\right)$ was determined for the beneficial insects (Table 4) and used to calculate selectivity ratios of the insecticides for the two beneficial insects (Table 5). The A. oleracea extract and compounds $\mathbf{1}, \mathbf{2}$ and $\mathbf{3}$ were selective to the predator S. saevissima and the pollinator $T$. angustula relative to $T$. absoluta, with a selectivity ratio $\left(S_{L} R_{50}\right)$ greater than 1.0 (Table 5). For the A. oleracea extract, the doses that caused $50 \%$ mortality of $T$. absoluta larvae were respectively 36 and $39 \%$ lower than the doses that caused the same mortality to S. saevissima and T. angustula. The estimated mortalities of $S$. saevissima and T. angustula by the $\mathrm{LD}_{80}$ of this extract to T. absoluta were 56 and $55 \%$ respectively (Table 5 ).

For compounds 1, 2 and 3, the doses that caused 50\% mortality of $T$. absoluta larvae were respectively 38, 39 and $64 \%$ lower than the doses that caused the same mortality to S. saevissima. Furthermore, the doses were 169, 37 and 35\% lower than the doses that caused the same mortality to $T$. angustula. The estimated mortality of S. saevissima and T. angustula by the $\mathrm{LD}_{80}$ of these compounds to T. absoluta ranged from 55 to $68 \%$. However, the $\mathrm{LD}_{50}$ of permethrin for T. absoluta was respectively 15.4 and 2366.7 times higher than the $\mathrm{LD}_{50}$ for $\mathrm{S}$. saevissima and T. angustula. These results indicate that permethrin is harmful to the beneficial insects. The estimated mortality of S. saevissima and T. angustula by the $\mathrm{LD}_{80}$ of this insecticide to T. absoluta was $100 \%$ (Table 5).

Based on the $S_{L} R_{50}$, the neem extract was selective to S. saevissima. However, the $\mathrm{DL}_{80}$ of neem extract to $T$. absoluta 
Table 3. Contact toxicity of Acmella oleracea hexane extract and of spilanthol (1), (E)- $N$-isobutylundeca-2-en-8,10-diynamide (2) and $(R, E)-N-(2-$ methylbutyl)undeca-2-en-8,10-diynamide (3) extracted from aerial parts of $A$. oleracea against Tuta absoluta $24 \mathrm{~h}$ after topical application

\begin{tabular}{|lcccccc} 
Treatments & $N^{\mathrm{a}}$ & $\mathrm{LD}_{50}\left(\mu \mathrm{g} \mathrm{mg}^{-1}\right)(95 \% \mathrm{FL})^{\mathrm{b}}$ & $\mathrm{LD}_{80}\left(\mu \mathrm{g} \mathrm{mg}^{-1}\right)(95 \% \mathrm{FL})^{\mathrm{b}}$ & Slope $\pm \mathrm{SE}$ & $\chi^{2}$ & $P$-value \\
\hline Acmella oleracea extract & 420 & $1.83(1.43-2.04)$ & $2.94(2.50-3.83)$ & $1.00 \pm 0.06$ & 4.50 & 0.480 \\
Compound 1 & 600 & $0.13(0.09-0.16)$ & $0.56(0.41-0.84)$ & $0.39 \pm 0.01$ & 1.69 & 0.998 \\
Compound 2 & 420 & $0.49(0.39-0.62)$ & $1.34(1.06-1.79)$ & $0.53 \pm 0.03$ & 2.01 & 0.987 \\
Compound 3 & 540 & $0.81(0.46-1.18)$ & $1.76(1.21-3.55)$ & $0.51 \pm 0.04$ & 1.06 & 0.998 \\
Azadirachta indica extract ${ }^{c}$ & 420 & $41.73(37.90-46.99)$ & $98.19(86.78-114.90)$ & $2.21 \pm 0.09$ & 6.27 & 0.370 \\
Permethrin $^{c}$ & 360 & $0.71(0.38-1.08)$ & $2.57(1.60-4.72)$ & $0.63 \pm 0.04$ & 7.70 & 0.103 \\
\hline a Number of insects tested. & & & & \\
b Lethal dose with 95\% fiducial limits (FL). & & & & \\
c Positive control. & & & & \\
\hline
\end{tabular}

Table 4. Contact toxicity of Acmella oleracea hexane extract and of spilanthol (1), (E)- $N$-isobutylundeca-2-en-8,10-diynamide (2) and $(R, E)-N-(2-$ methylbutyl)undeca-2-en-8,10-diynamide (3) extracted from aerial parts of $A$. oleracea against Solenopsis saevissima and Tetragonisca angustula $24 \mathrm{~h}$ after topical application

\begin{tabular}{|c|c|c|c|c|c|c|}
\hline Treatments & $N^{\mathrm{a}}$ & $\mathrm{LD}_{50}\left(\mu \mathrm{g} \mathrm{mg}^{-1}\right)(95 \% \mathrm{FL})^{\mathrm{b}}$ & $\mathrm{LD}_{80}\left(\mu \mathrm{g} \mathrm{mg}^{-1}\right)(95 \% \mathrm{FL})^{\mathrm{b}}$ & Slope \pm SE & $\chi^{2}$ & $P$-value \\
\hline \multicolumn{7}{|c|}{ Solenopsis saevissima } \\
\hline Acmella oleracea extract & 420 & $2.48(2.14-2.84)$ & $5.47(4.71-6.54)$ & $0.68 \pm 0.03$ & 3.75 & 0.967 \\
\hline Compound 1 & 420 & $0.18(0.13-0.23)$ & $1.12(0.73-2.24)$ & $0.44 \pm 0.03$ & 6.02 & 0.450 \\
\hline Compound 2 & 360 & $0.67(0.54-0.82)$ & $2.22(1.78-2.88)$ & $0.47 \pm 0.03$ & 6.37 & 0.278 \\
\hline Compound 3 & 420 & $1.33(1.06-1.63)$ & $4.40(3.53-5.70)$ & $0.47 \pm 0.03$ & 6.12 & 0.354 \\
\hline Azadirachta indica extract ${ }^{c}$ & 360 & $72.65(68.47-76.63)$ & $92.50(87.39-99.10)$ & $2.76 \pm 0.25$ & 1.42 & 0.999 \\
\hline Permethrinc & 300 & $0.046(0.029-0.073)$ & $1.458(0.682-4.453)$ & $0.28 \pm 0.02$ & 4.69 & 0.450 \\
\hline \multicolumn{7}{|c|}{ Tetragonisca angustula } \\
\hline Acmella oleracea extract & 420 & $2.55(2.22-2.86)$ & $4.28(3.82-4.90)$ & $1.08 \pm 0.07$ & 3.62 & 0.608 \\
\hline Compound 1 & 420 & $0.35(0.29-0.42)$ & $0.81(0.67-1.01)$ & $0.68 \pm 0.02$ & 1.62 & 0.998 \\
\hline Compound 2 & 360 & $0.67(0.48-0.86)$ & $2.02(1.55-2.91)$ & $0.55 \pm 0.05$ & 7.49 & 0.112 \\
\hline Compound 3 & 420 & $1.10(0.89-1.33)$ & $2.26(2.16-3.47)$ & $0.58 \pm 0.03$ & 1.81 & 0.994 \\
\hline Azadirachta indica extract ${ }^{c}$ & 360 & $29.52(25.23-34.15)$ & $71.04(59.62-88.92)$ & $0.68 \pm 0.05$ & 6.93 & 0.399 \\
\hline Permethrin ${ }^{c}$ & 300 & $0.0003(0.0002-0.0005)$ & $0.002(0.001-0.004)$ & $0.40 \pm 0.02$ & 4.95 & 0.427 \\
\hline
\end{tabular}

caused a mortality of 84 and $98 \%$ to S. saevissima and T. angustula respectively (Table 5).

\section{DISCUSSION}

The plant species showing the highest insecticidal activity in the present study was the toothache plant Acmella oleracea. Furthermore, the activity was higher in the hexane extract than in the ethanol extract. The insecticide activity of $A$. oleraceae extracts has been reported for several insect vectors of diseases such as Aedes aegypti Linn, Anopheles stephensi Liston, Anopheles culicifacies Giles and Culex quinquefasciatus Say (Diptera: Culicidae). ${ }^{10-13}$ However, there is no thorough study on the effect of this plant on insect pests of agricultural crops.

The bioactivity of $A$. oleracea is due to alkamides present in the plant. The main active amide in the plant is an isobutylamide, $(2 E, 6 Z, 8 E)$ - $N$-isobutyldeca-2,6,8-trienamide, commonly known as spilanthol. ${ }^{22,23}$ These alkamides have a pungent effect and have been studied for various purposes. The flowers and leaves of $A$. olerace a are used in cooking and in popular medicine, mainly as an analgesic for toothache. The spilanthol is known for having several chemical and pharmaceutical applications in addition to the analgesic for toothache already mentioned. It is used for the treatment of aphtha and herpes, for stomatitis and infections in the throat, in treatment of tuberculosis, as a sialagogue, as a fungistat and fungicide against Aspergillus spp., as an antimutagenic agent and as a cicatrisant. ${ }^{24-26}$

The results also showed that the alkamides evaluated in this study have the potential to control arthropods of agricultural importance. Three alkamides were identified in the bioactive fractions of the hexane extract of $A$. oleracea [spilanthol, (E)- $N$-isobutylundeca-2-en-8,10-diynamide and $(R, E)-N-(2$ methylbutyl)undeca-2-en-8,10-diynamide]. This study evaluated the effect of $A$. oleracea on T. absoluta, an important pest of tomato in the world. The results showed that all of the compounds isolated had high insecticidal activity that was at least as toxic as permethrin, a pyrethroid recommended for control of T. absoluta. Furthermore, the compounds were far more toxic than the neem extract. The high efficiency of these compounds, combined with the ready availability from natural sources and the friendlier environmental footprint, makes this plant an excellent candidate as a future natural insecticide.

The results from this study showed that alkamides $\mathbf{1}, \mathbf{2}$ and $\mathbf{3}$ were selective to S. saevissima and T. angustula. The tolerance of 
Table 5. Risk assessment of Acmella oleracea hexane extract and of spilanthol (1), (E)- $N$-isobutylundeca-2-en-8,10-diynamide (2) and $(R, E)$ - $N$ (2-methylbutyl)undeca-2-en-8,10-diynamide (3) extracted from aerial parts of A. oleracea on adults of Solenopsis saevissima and Tetragonisca angustula

\begin{tabular}{|c|c|c|c|c|c|c|}
\hline \multirow[b]{2}{*}{ Treatment } & \multicolumn{3}{|c|}{ Solenopsis saevissima } & \multicolumn{3}{|c|}{ Tetragonisca angustula } \\
\hline & $\mathrm{S}_{\mathrm{L}} \mathrm{R}_{50} \mathrm{a}^{\mathrm{a}}$ & Category of insecticide & Mortality $(\%)^{\mathrm{b}}$ & $\mathrm{S}_{\mathrm{L}} \mathrm{R}_{50}{ }^{\mathrm{a}}$ & Category of insecticide & Mortality (\%) \\
\hline Acmella oleracea extract & 1.36 & Selective & 56 & 1.39 & Selective & 55 \\
\hline Compound 1 & 1.38 & Selective & 68 & 2.69 & Selective & 58 \\
\hline Compound 2 & 1.39 & Selective & 57 & 1.37 & Selective & 62 \\
\hline Compound 3 & 1.64 & Selective & 55 & 1.35 & Selective & 59 \\
\hline Azadirachta indica extract ${ }^{c}$ & 1.74 & Selective & 84 & 0.70 & Non-selective & 98 \\
\hline Permethrin $^{c}$ & 0.00042 & Non-selective & 100 & 0.065 & Non-selective & 100 \\
\hline
\end{tabular}

beneficial insects to alkamides could be related to lower rates of insecticide penetration through the integument, higher rates of insecticide breakdown and relative insensitivity of the target site in natural enemies compared with T. absoluta. ${ }^{27-31}$

The selectivity provided by alkamides to S. saevissima and $T$. angustula suggests that the use of these compounds to control T. absoluta presents a low risk to these beneficial insects. Furthermore, the results from this study showed that all compounds had a lower toxicity than permethrin (insecticide already used to control T. absoluta) to all non-target species studied. This finding indicates that the alkamides are less harmful to the beneficial insects. Thus, to preserve the predator and the pollinator investigated in this study, the use of these compounds for pest control can be recommended as a strategy to manage these beneficial insects.

Physiological selectivity is based on the use of insecticides that are more toxic to the target pest than the natural enemies and should always be considered when controlling pests. Furthermore, the principles of ecological selectivity should also be considered. ${ }^{32,33}$ The ecological selectivity is related to the different methods of applying insecticides as a means to minimise exposure of natural enemies to the insecticide. ${ }^{32}$ It is of utmost importance to use selective insecticides to preserve the beneficial species in the ecosystem, and it is necessary to resort to strategies that will enable the achievement of ecological selectivity even if the use of selective insecticides is not possible. With ecological selectivity, an insecticide can be applied with a methodology designed to make it selective. The low stability of botanical pesticides and consequent rapid degradation in the environment are characteristics that favour ecological selectivity, because they reduce the exposure time of beneficial organisms to toxic compounds.

The mechanism of action of active alkamides found in $A$. oleracea has not yet been determined. It appears to affect the nervous system, as evident from abnormal movement such as uncoordinated muscular activity. This effect suggests that the compounds disturb nerve conduction somewhere. The analgesic activity of spilanthol in humans has been attributed to an increased GABA release in the temporal cerebral cortex, ${ }^{34}$ while other bioactive alkylamides are acting on voltage-gated sodium channels. ${ }^{35}$ The mortality after short exposure to the compounds indicates that alkamides greatly disturb the ongoing processes of histolysis of larval tissues. Saraf and Dixit ${ }^{12}$ observed rapid mortality of pupae of A. culicifacies, C. quinquefasciatus and A. aegypti when exposed to spilanthol. These results suggest that spilanthol interferes in histolysis and histogenesis processes. Further research is needed to address this question.

Overall, the results of this research indicate that the $A$. oleracea extract is the most promising among the plant extracts studied. The active alkamides from $A$. oleracea can be a potential alternative for controlling T. absoluta and should be studied further for other agricultural pests. All compounds presented high insecticidal activity for the insect pest T. absoluta and selectivity for beneficial insects S. saevissima and T. angustula. Given the vital need for environmentally friendly chemicals that represent new insecticide groups with novel mechanisms of action, low persistence in the field and low toxicity to mammals and non-target species, the feasibility and impacts of using natural chemicals in pest management programmes require further attention. It must be remembered, however, that the biological activity of a chemical is a function of its structure rather than its origin. The biological properties of a chemical depend on its structure and the way in which the chemical is used. Bioactive alkamides from $A$. oleracea have been found to be harmless to the majority of vertebrates and lethal to invertebrates. ${ }^{36,37}$ Because $A$. oleracea is widely used as both food and folk medicine in its region of origin, it is assumed that its toxicity to humans is extremely low. However, the actual risks of using these natural products should be identified. Therefore, to assess the feasibility and impacts of using $A$. oleracea alkamides in agriculture, more research on the effects on humans and the environment should be performed.

\section{CONCLUSION}

The hexane extract of $A$. oleraceae showed high insecticidal activity and can be used to control T. absoluta in organic or conventional crops. Quantification of $\mathrm{LD}_{50}$ values of isolated alkamides of $A$. oleracea against $T$. absoluta showed that alkamides could serve as potent insecticides for T. absoluta control programmes. The spilanthol was the main alkamide active isolated. This alkamide is the most promising, as it had the highest insecticidal activity and was selective to non-target organisms. Therefore, spilanthol and the other alkamides isolated are potential pest management tools likely to have their insecticide activity improved through organic synthesis guided by studies of quantitative structure-activity relationships. 


\section{ACKNOWLEDGEMENT}

The authors are grateful to the Conselho Nacional de Desenvolvimento Científico e Tecnológico - CNPq/Brazil for financial support (doctoral fellowship).

\section{REFERENCES}

1 Suinaga FA, Picanço M, Jham GN and Brommonschenkel SH, Causas químicas de resistência de Lycopersicum peruvianum (L.) a Tuta absoluta (Meyrick) (Lepidoptera: Gelechiidae). An Soc Entomol Brasil 28:313-321 (1999).

2 Souza JC, Reis PR and Salgado LO, Traça-do-tomateiro: histórico, reconhecimento, biologia, prejuízos e controle. Belo Horizonte, Empresa de Pesquisa Agropecuária de Minas Gerais, 15 pp. (1983).

3 Seplyarsky V, Weiss $\mathrm{M}$ and Haberman A, Tuta absoluta Povolny (Lepidoptera: Gelechiidae), a new invasive species in Israel. Phytoparasitica 38:445-446 (2010).

4 Desneux N, Wajnberg E, Wyckhuys KAG, Burgio G, Arpaia S, NarváezVasquez CA, et al, Biological invasion of european tomato crops by Tuta absoluta: ecology, geographic expansion and prospects for biological control. J Pest Sci 83:197-215 (2010).

5 KılıçT, First record of Tuta absoluta in Turkey. Phytoparasitica 38:243-244 (2010).

6 Lietti MMM, Botto $\mathrm{E}$ and Alzogaray RA, Insecticide resistance in Argentine populations of Tuta absoluta (Meyrick) (Lepidoptera: Gelechiidae). Neotrop Entomol 34:113-119 (2005).

7 Belmain SR, Neal GE, Ray DE and Golop P, Insecticidal and vertebrate toxicity associated with ethnobotanicals used as post-harvest protectants in Ghana. Food Chem Toxicol 39:287-291 (2001).

8 Balick MJ, Elisabetsky E and Laird SA, Medicinal Resources of the Tropical Forest: Biodiversity and its Importance to Human Health. Columbia University Press, New York, NY, 440 pp. (1995).

9 Sharma G, Gupta V, Sharma S, Shrivastava B and Bairva R, Toothache plant Spilanthes Acmella Murr.: a review. J Natura Conscientia 1:135-142 (2010).

10 Ramsewak RS, Erickson AJ and Nair MG, Bioactive $N$-isobutylamides from the flower buds of Spilanthes acmella. Phytochemistry 51:729-732 (1999).

11 Pandey V, Agrawal V, Raghavendra K and Dash AP, Strong larvicidal activity of three species of Spilanthes against malaria (Anopheles stephensi Liston, Anopheles culicifacies, species C) and filaria vector (Culex quinquefasciatus Say). J Parasitol Res 102:171-174 (2007).

12 Saraf DK and Dixit VK, Spilanthes acmella Murr: study on its extract spilanthol as larvicidal compound. Asian J Exp Sci 16:9-19 (2002).

13 Amer $\mathrm{A}$ and Mehlhorn $\mathrm{H}$, Larvicidal effects of various essential oils against Aedes, Anopheles, and Culex larvae (Diptera, Culicidae). Parasitol Res 99:466-472 (2006).

14 Cornell HV and Hawkins BA, Survival patterns and mortality sources of herbivorous insects: some demographic trends. Amer Nat 145:563-593 (1995).

15 Malagodi-Braga KS and Kleinert AMP, Could Tetragonisca angustula Latreille (Apinae, Meliponini) be used as strawberry pollinator in greenhouses? Aust J Agric Res 55:771-773 (2004).

16 Way MJ and Khoo KC, Role of ants in pest management. Annu Rev Entomol 37:479-503 (1992).

17 SAS/STAT User's Guide, Version 9.1. SAS Institute, Cary, NC (2002).

18 Young LJ and Young JH, Statistical Ecology: a Population Perspective. Kluwer Academic, Boston, MA, 584 pp. (1998).
19 Bacci L, Picanço MC, Rosado JF, Silva GA, Crespo ALB, Pereira EJG, et al, Conservation of natural enemies in brassica crops: comparative selectivity of insecticides in the management of Brevicoryne brassicae (Hemiptera: Sternorrhyncha: Aphididae). Appl Entomol Zool 44:103-113 (2009).

20 Nakatani $\mathrm{N}$ and Nagashima M, Pungent alkamides from Spilanthes acmella L. var. oleracea Clarke. Biosc Biotech Biochem 56:759-762 (1992).

21 Bauer R, Remiger $\mathrm{P}$ and Wagner $\mathrm{H}$, Alkamides from the roots of Echinacea angustifolia. Phytochemistry 28:505-508 (1989).

22 Ley JP, Blings M, Krammer G, Reinders G, Schmidt CO and Bertram HJ, Isolation and synthesis of acmellonate, a new unsaturated long chain 2-ketol ester from Spilanthes acmella. NatProd Res 20:798-804 (2006).

23 Wu LC, Fan NC, Lin MH, Chu IR, Huang SJ, Hu CY, et al, Anti-inflammatory effect of spilanthol from Spilanthes acmella on murine macrophage by down-regulating LPS-induced inflammatory mediators. J Agric Food Chem 56:2341 - 2349 (2008).

24 Haw AB and Keng CL, Micropropagation of Spilanthes acmella L., a bioinsecticide plant, through proliferation of multiple shoots. J Appl Hortic 5:65-68 (2003).

25 Coutinho LN, Aparecido CC and Figueiredo MB, Galls and deformation on jambu (Spilanthes oleraceae) caused by Tecaphora spilanthes (Ustilaginales). Summa Phytopathol 32:283-285 (2006).

26 Singh SK, Rai MK, Asthana P, Pandey S, Jaiswal VS and Jaiswal U, Plant regeneration from alginate-encapsulated shoot tips of Spilanthes acmella (L.) Murr., a medicinally important and herbal pesticidal plant species. Acta Physiol Plant 31:649-653 (2009).

27 Guedes RNC, Resistência de insetos a inseticidas, in Manejo Integrado de Doenças e Pragas, ed. by Zambolin L. Editora UFV, Viçosa, MG, Brazil, pp. $101-107$ (1999).

28 YuSJ, Selectivity of insecticides to the spined bug (Heteroptera: Pentatomidae) and its lepidopterous prey. J Econ Entomol 81:119-122 (1988).

29 Hackman RH, Chemistry of the cuticle, in The Physiology of Insecta, ed. by Rockstein M. Academic Press, New York, NY, pp. 216-270 (1974).

30 Hollingworth RM, The biochemical and physiological basis of selective toxicity, in Insecticide Biochemistry and Physiology, ed. by Wilkinson CF. Plenum Press, New York, NY, pp. 431 -506 (1976).

31 Leite GLD, Picanco M, Guedes RNC and Gusmão MR, Selectivity of insecticides with and without mineral oil to Brachygastralecheguana (Hymenoptera:Vespidae), a predator of Tuta absoluta (Lepidoptera: Gelechiidae). Ceiba 39:191 - 194 (1998).

32 Ripper WE, Greenslade RM and Hartley GS, Selective insecticides and biological control. J Econ Entomol 44:448-459 (1951).

33 O'Brien RD, Toxic Phosphorus Esters. Academic Press, New York, NY, 434 pp. (1960).

34 Rios MY, Aguilar-Guadarrama AB and Gutierrez MD, Analgesic activity of affinin, an alkamide from Heliopsis longipes (Compositae). J Ethnopharmaco 110:364-367 (2007).

35 Gertsch J, Immunmodulatory lipids in plants: plant fatty acid amides and the human endocannabinoid system. Planta Med 74:638-650 (2008).

36 Pandey V and Agrawal V, Efficient micropropagation protocol in Spilanthes acmella L. possessing strong antimalarial activity. In Vitro Cell Dev Biol Plant 45:491 -499 (2009).

37 Watt PM and Brayer-Brandwijk MC, The Medicinal and Poisonous Plants of Southern and Eastern Africa. E\&S Livingstone, Edinburgh, UK, 1457 pp. (1962). 